\title{
Conexões
}

\section{Teoria do jogo: a dimensão lúdica da existência humana}

Rogério de Melo Grillo ${ }^{1}$

Elaine Prodócimo ${ }^{1}$

\section{RESUMO}

A presente resenha tem como escopo analisar, de maneira descritiva e crítica, o livro "Teoria do Jogo: a dimensão lúdica da existência humana", de Jeferson J. M. Retondar. Vale ressaltar que o presente livro é composto por cinco capítulos e visa colaborar significativamente com o debate concernente à importância do jogo na formação dos indivíduos. Para tanto, traz uma análise epistemológica do jogo, que sustenta um paradigma de Educação pelo Jogo.

Palavras-Chave: Jogo. Educação pelo jogo. Lúdico.

\footnotetext{
${ }^{1}$ Universidade Estadual de Campinas Recebido em: 08 maio 2017 Aprovado em: 31. ago. 2016

Contato: rogerio.grillo@ hotmail.com 


\section{Game theory: the ludic dimension of human}

\section{existence}

\section{ABSTRACT}

The present review aims to analyze, descriptively and critically, the book "Game theory: the ludic dimension of human existence", by Jeferson J. M. Retondar. This book is composed of five chapters and aims to contribute significantly to the debate concerning the importance of gaming in the formation of the individuals. Therefore, it brings an epistemological analysis of the game, that supports a paradigm of Education through Play.

Keywords: Game. Education through Play. Ludic.

\section{Teoría del Juego: la dimensión lúdica de la existencia humana}

\section{RESUMEN}

La presente reseña tiene como objetivo analizar, de manera descriptiva y crítica, el libro "Teoría del Juego: la dimensión lúdica de la existencia humana", de Jeferson J. M. Retondar. Es importante resaltar que el presente libro es compuesto por cinco capítulos y pretende colaborar significativamente con el debate concerniente a la importancia del juego en la formación de los individuos. Para ello, trae un análisis epistemológico del juego, que sostiene un paradigma de Educación por el Juego.

Palabras Clave: Juego. Educación por el juego. Lúdico. 
O livro "Teoria do jogo" de Retondar (2007) visa colaborar expressivamente com o debate concernente à importância do jogo na formação dos indivíduos. Para tanto, o autor toma como ponto de partida, para suas reflexões, uma análise epistemológica do jogo com o objetivo de sustentar sua concepção de Educação pelo Jogo. Subsequentemente, esquematiza, de maneira sistemática, pontos relevantes sobre a formação humana pelo jogo, segundo uma perspectiva ética, moral, estética e lúdica.

Destarte, o objetivo do autor é "apresentar alguns possíveis argumentos na defesa do jogo como conhecimento em si mesmo e como caminho que pode levar a outros conhecimentos tão importantes como o próprio jogo" (RETONDAR, 2007, p. 89).

Nesse contexto, o livro é dividido em cinco capítulos, sendo: Introdução; O Jogo; Os Jogos de Competição (âgon), os Jogos de Sorte (alea), os Jogos de Simulacro (mimicry) e os Jogos de Vertigem (ilinx); A Educação pelo Jogo; O elogio ao Jogo.

No primeiro capítulo (Introdução), Retondar (2007, p. 9) elabora uma breve apresentação do tema central de seu livro, sugerindo algumas definições atinentes ao jogo e ao jogar, tais como: “[...] o jogo é antes de tudo uma atividade, isto é, uma ação humana pautada por uma intenção que se justifica por si mesma”. Em outro momento, explana que jogar é "dizer de maneira lúdica aquilo que só pode ser dito através do discurso não verbal em situações imaginárias. [Com isso], o ato de jogar revela subjetividades no presente e aponta pistas para o futuro" (RETONDAR, 2007, p. 12). De resto, o autor depreende que o jogo é um fenômeno social necessário ao ser humano e, apesar de seu caráter elusivo, é fenômeno social e cultural fundado em uma atividade simbólica carregada de representações, intersubjetividades e formas de expressividade daquilo que é profundamente sentido.

No segundo capítulo, Retondar (2007), por meio de uma análise acerca das ideias de Colas Duflo, infere que o jogo pode ser compreendido, no bojo da Filosofia, da História e da Antropologia, conforme três grandes apropriações: Ética, Científica e Estética/Pedagógica.

Tencionando analisar estas três grandes apropriações, o autor busca na obra Homo Ludens de Johan Huizinga, embasamento teórico para construir uma síntese geral do jogo, que auxilie "a pensar o jogo como um componente universal, isto é, presente em todas as culturas e se manifestando de maneiras diferentes nas diversas sociedades (RETONDAR, 2007, p. 17).

Assim, Retondar (2007) visa ampliar as características formais do jogo propostas por Huizinga, não tão somente no sentido de apresentá-las, mas de ressignificá-las, construindo uma concepção de Educação pelo Jogo. Nesse viés, o autor exemplifica que todo jogo, seja no âmbito estrutural ou no próprio movimento do jogar, possui 
características formais e também facetas não formais que se coadunam. Sumariamente, as propriedades formais e não formais arroladas são: regras, incerteza, tensão, tomada de decisão, espaço e tempo próprio, espírito lúdico, comportamento agonístico, acaso, imaginação, abstração, etc.

Por conseguinte, Retondar (2007, p. 32), sob a égide da obra "O jogador" de Dostoiévski, elabora uma possível definição para o lúdico: "viver com intensidade uma experiência impossível de ser descrita racionalmente". Tal definição seria, precipuamente, um predicado que "transpassa" as características formais e não formais do jogo, tanto num sentido teórico (análise externa de jogo), quanto na própria situação de jogo (jogo jogado).

De resto, o autor conclui o segundo capítulo afirmando que qualquer manifestação social que possua regras, espaço e tempo próprio, voluntariedade, evasão do cotidiano e tenha um fim em si (atividade improdutiva), é categoricamente jogo.

O terceiro capítulo é dividido em quatro seções. Retondar (2007) utiliza das quatro grandes categorias de jogo criadas por Roger Caillois, sendo uma para cada seção. Entrementes, o autor não objetiva tecer uma classificação pormenorizada, pelo contrário, busca potencializar cada classificação, com o intuito de, a priori, corroborar com as ideias levantadas no capítulo anterior e, a posteriori, construir um paradigma de Educação pelo Jogo, no qual contemple o jogo como conhecimento em si e meio de educar o indivíduo.

Dessa forma, Retondar (2007), na primeira seção, atrela os Jogos de Competição (âgon) a definição de vontade de potência ideada por Nietzsche. Assim, defende a competição como algo inseparável do jogo e, igualmente, como uma forma do jogador superar a si próprio. No entanto, o autor não defende a competição veiculada rigorosamente pela sociedade de consumo, ao contrário, ele descortina toda concepção errônea sobre a competição, ao afirmar que esta manifestação não é boa nem má. Nesse sentido, o problema está nos indivíduos que se apropriam desta manifestação e do uso que fazem dela.

Na segunda seção, pertinente aos Jogos de Sorte (alea), Retondar (2007) se sustenta a partir da obra "O jogador" de Dostoiévski, dado que a personagem principal dessa obra é viciada em jogos de sorte/azar. Assim, alude que nos jogos de alea a evasão lúdica da realidade é potencializada pela relação do indivíduo com o jogo, em que este está à mercê do destino, ou seja, numa realidade neutra que nem sempre o indivíduo mais forte, hábil ou preparado vence.

Na terceira seção, os Jogos de Simulacro (mimicry) são apresentados por Retondar (2007) como uma encarnação ou representação de uma personagem fictícia. Nesse contexto, o importante é representar um papel, assumir imaginariamente o lugar 
do outro a partir de si mesmo. É "internalizar com clareza as regras de comportamento e da natureza que gravitam em torno do objeto representado" (RETONDAR, 2007, p. 48).

Ademais, o autor analisa que os jogos de simulacro são, precipuamente, motivados pelo espírito lúdico, cuja única finalidade é a autossatisfação, a realização de desejos, sonhos e alegrias, e, é claro, a busca pelo transe. Portanto, o escopo deste tipo de jogo é transitar entre o real e o imaginário, é ser e não ser ao mesmo tempo.

Na última seção, atinente aos Jogos de Vertigem (ilinx), Retondar (2007) explica que nesta categoria de jogo, o objetivo principal é obter prazer na vertigem, no mal-estar ou no pânico momentâneo. Além disso, neste tipo de jogo, "o espírito lúdico tende a se manifestar arrastando os indivíduos para a emoção pura” (RETONDAR, 2007, p. 53).

No quarto capítulo, cerne do livro, Retondar propõe "refletir sobre a importância do jogo na formação dos sujeitos" (RETONDAR, 2007, p. 55-56), segundo uma perspectiva ética e estética, ou seja, conforme "alguns pontos significativos do jogo como meio de formação moral e como experiência do belo para a vida).

Nessa perspectiva, o autor analisa as especificidades formais e não formais do jogo, com o escopo de arquitetar uma concepção de Educação pelo Jogo, fundamentada na ideia de jogo como conhecimento (fim em si) e como método (meio) para a intervenção profissional.

Para tanto, subdivide o capítulo em quatro seções: voluntariedade; regras; relação espácio-temporal; e, evasão da vida real. De modo sintético, em cada seção, o autor arrola as potencialidades e possibilidades de cada uma das quatro características supramencionadas na formação do indivíduo e, pari passu, relaciona-as ao processo de intervenção profissional.

A partir disso, o autor sintetiza que uma Educação pelo Jogo deve, prioritariamente, contemplar a autonomia e a tomada de decisão, a construção e a conservação de uma estrutura composta por regras e objetivos, a delimitação de um espaço e tempo próprios e, por fim, a evasão da vida real (fuga, alívio, catarse). É importante ressaltar que Retondar (2007), por meio destes predicados referentes ao jogo, tem por objetivo uma formação ética, estética, lúdica, moral, que propenda a formação humana na sua totalidade.

No último capítulo, "O elogio ao jogo", Retondar (2007) defende que o jogo é uma construção humana, desse modo, está sujeito a diversos significados e sentidos, segundo o universo cultural e social à qual cada indivíduo está inserido. Ademais, enfatiza que o jogo é um conhecimento que potencializa a dimensão lúdica da existência humana.

Conexões: Educ. Fís., Esporte e Saúde, Campinas: SP, v. 15, n. 2, p. 251-256, abr./jun. 2017. ISSN: 1980-9030 
Nesse viés, o autor propõe que educar um indivíduo pelo jogo é criar condições objetivas (construção de regras, espaço físico, tempo, material etc.), para que este possa vivenciar a experiência lúdica na sua totalidade, possibilitando o êxtase, a catarse, a alegria, a autonomia, a liberdade, a vivência do belo, e, mormente, possibilitar um meio concreto de potencializar a vida.

Pode-se analisar que o livro contribui substancialmente para uma análise filosófica do jogo, em específico, no que tocante à formação ética e estética. Dessa forma, contribuindo para além do discurso a respeito do jogo e do desenvolvimento motor/cognitivo tão veiculado em várias obras sobre o jogo, o lúdico, o brinquedo, a brincadeira e a cultura lúdica no âmbito da Educação Física e da Pedagogia. Com isso, contribui significativamente para uma reflexão teórico e prática respeitante ao jogo e ao ato de jogar.

O livro igualmente colabora para uma discussão mais criteriosa concernente à noção de jogo e de suas características formais e não formais. Vale dizer que tais características são constantemente citadas em artigos, livros, teses e dissertações, porém tão pouco analisadas acuradamente.

A despeito dessa contribuição, o autor não analisa as características formais e não formais do jogo de maneira a se concatenarem dinamicamente. Dessarte, não houve um olhar mais atento ao "jogo jogado", em que as aludidas características formais e não formais se fazem presentes, ora latentes, ora mais manifestas.

É preciso enfatizar que o lúdico não fica bem depreendido no livro, tendo em vista que a definição proposta por Retondar (2007) é, de certo modo, abrangente e superficial, redundando em uma concepção polarizada aos sentimentos de alegria, prazer e paixão.

Em outras palavras, o autor poderia buscar na obra "O jogador" de Dostoiévski uma noção sobre o lúdico, posto que há na referida obra uma concepção de lúdico, talvez de maneira subentendida, como um movimento intenso e único. Em outras palavras, o lúdico seria um sentimento inexplicável antes de jogar, um arrebatamento e um dinamismo durante o jogar, e, enfim, um conflito (prazer, desprazer, alegria, tristeza) após o jogar.

\section{REFERÊNCIAS}

RETONDAR, J. J. M. Teoria do jogo: a dimensão lúdica da existência humana. Petrópolis: Vozes, 2007. 

ERROR: syntaxerror

OFFENDING COMMAND: --nostringval--

\section{STACK :}

/Title

()

Subject

(D:20171025160457-02'00')

/ModDate

( )

/Keywords

(PDFCreator Version 0.9.5)

/Creator

(D:20171025160457-02'00')

/CreationDate

(dulce)

/Author

-mark- 